\title{
O CONCEITO DE LUGAR NA GEOGRA- FIA CULTURAL-HUMANISTA: UMA CONTRIBUIÇÃO PARA A GEOGRAFIA CONTEMPORÂNEA
}

\author{
WERTHER HOLZER* \\ Universidade Federal Fluminense
}

"Lugar", conceito espacial que durante longo tempo foi utilizado pelos geógrafos para expressar o sentido locacional de um determinado sítio. Devido a esta definição foi relegado a um plano secundário em relação a outros conceitos espaciais como paisagem, espaço, e território. Hoje, no entanto, "lugar" é considerado conceito fundamental no estudo da geografia. Já debati sobre esta mudança de perspectiva conceitual em outro texto (HOLZER, 1999). Aqui procurarei relacionar o conceito de "lugar" com a investigação que determinado coletivo dedicado à ciência geográfica fez dos conteúdos teóricos e métodos preconizados pela fenomenologia, me deterei na contribuição fundamental de um único autor: Tuan.

Esta investigação iniciou-se na década de 20 tornando-se mais dinâmica na década de 60. Considerada esta trajetória, é preciso refletir sobre o modo como este aporte teórico conceitual vem sendo incorporado pelos geógrafos. Ao falarmos de fenomenologia na geografia devemos nos reportar à obra de Carl Sauer, que já em 1925 se referia à fenomenologia em artigo intitulado "A Morfologia da Paisagem" (1998 [1925]). Neste artigo, dedicado às questões teóricas mais palpitantes para a

\footnotetext{
* Professor do Departamento de Arquitetura da UFF
} 
geografia naquele momento, o autor inicia procurando delimitar o "campo da geografia", e começa a fazê-lo apoiado na "visão fenomenológica da ciência".

Segundo o aporte bibliográfico escolhido pelo autor, uma abordagem científica fenomenológica exige a determinação inicial dos limites e qualidades de um fato que só podem ser compreendidos quando observados em suas relações. As ciências se constituiriam enquanto seções ingênuas (naïve) da realidade. Ingênuas porque o agrupamento dos grandes campos do conhecimento se dá a partir da experiência humana e não pela pesquisa do especialista. No conjunto destes grandes campos do conhecimento a geografia estaria envolvida, a partir de uma "realidade ingenuamente perceptível", com o estudo da área ou paisagem, constituída pelos fatos do lugar. (SAUER, 1998 [1925], 13-15).

Esta reflexão teórica iria se sofisticando ao longo das décadas seguintes na medida em que a "Geografia Cultural", enquanto produto acadêmico desta reflexão, se tornava a disciplina mais lecionada nos cursos de geografia norte-americanos e a que mais gerava pesquisas de campo. Neste contexto não se discutia mais o aporte teórico, mas manteve-se seus fundamentos de se observar o fator em suas relações (espaço vivido) e de se considerar que a geografia estava "além da ciência", isto é, que extrapolava os métodos de pesquisa científica impostos pelo positivismo, idéia que Sauer já enunciara neste primeiro artigo (SAUER, 1998 [1925], 61), e na qual insistiria até o fim da vida (SAUER, 1981 [1967], 244).

Outro autor que não pode ser ignorado é Eric Dardel que produziu uma obra em que a fenomenologia existencialista é o suporte teórico. Ele não aceitava que a geografia fosse vista como uma disciplina científica nos moldes positivistas. Para ele a geografia se refere à inserção do homem-no-mundo, de modo que não pode lidar apenas com aspectos objetivos ligados a um espaço geometrizado. Ela pressupõe um campo de estudos próprio que se refere à existência humana na Terra, a partir de um objeto fenomenologicamente determinado: o "espaço geográfico", que tem como elemento essencial a "geograficidade", definida como uma "geografia vivida em ato" a partir da exploração do mundo e das ligações de cada homem com sua terra natal. (DARDEL, 1990 [1952], 2).

O livro de Dardel seria praticamente esquecido. Redescoberto por Relph, que o cita em sua tese The Phenomenon of Place de 1973, ajudaria a despertar a curiosidade sobre a fenomenologia numa jovem geração de geógrafos ligados à Geografia Cultural. Esta geração via os campos de pesquisa tradicionais da disciplina se esgotarem, ou perderem a hegemonia para a "geografia quantitativa", como está muito bem enunciado por Mikesell (1978). Deste modo incitados primeiramente por Relph (1970), e posteriormente por Tuan (1971 b), passam a procurar na fenomenologia procedimentos úteis para a "descrição do mundo cotidiano".

Relph valorizava na fenomenologia a descrição das essências das estruturas temáticas, o exame dos modos como aparecem os objetos; o estudo da constituição dos fenômenos na consciência; a críticas ao cientificismo, seguidas de apelos do autor pela adoção de um aporte radical; a valorização da intersubjetividade e da 
intencionalidade; o reconhecimento de que este campo da filosofia tinha importância para o estudo do pensamento e do conhecimento, e na valorização de condutas de vida.

Em outros artigos tive a oportunidade de abordar como estas preocupações acabaram por originar a geografia humanista, explicitamente considerada como campo autônomo em 1976 (HOLZER, 1993; 1996).

O fato é que as dificuldades, talvez na compreensão, mas certamente na aplicação do método levariam a propostas de sua utilização de modo implícito (RELPH, 1976, nota 7, pag. 7; TUAN, 1976), ou a propostas de descarte de determinadas fenomenologias, a pura de Husserl, ou a hermenêutica, de Ricoeur, com a manutenção apenas do "espírito" da filosofia, que estaria contido no conceito de "Lebenswelt", a vida cotidiana (BUTTIMER 1976), que os geógrafos franceses, sem tantas preocupações de delimitações teórico-conceituais, souberam muito bem estudar a partir do "espace vecú".

Os três tipos de pesquisa citados acima, muito marcados pelas perspectivas da geografia cultural e da geografia histórica e, também, pelo conceito de "paisagem cultural" contribuíram de maneira modesta para a consolidação da geografia humanista. A fenomenologia e o existencialismo, como base filosófica, e a escolha do "lugar" como conceito espacial que mais atendia aos seus propósitos, seriam apropriados por alguns expoentes do coletivo - Tuan, Buttimer e Relph - empenhados na renovação da geografia cultural, ou melhor, da própria geografia, além de pretender o reconhecimento da geografia humanista como campo autônomo de estudos.

Na primeira metade da década de 70 podemos destacar os nomes de Tuan e de Butttimer como os que mais contribuíram na busca por uma identidade própria para a geografia humanista. Esses autores foram pioneiros na utilização dos conceitos de lugar e de mundo vivido, ambos associados a uma base teórica fenomenológicoexistencialista, aporte que mais tarde permitiria a identificação de seus trabalhos como humanistas.

Por esta época Tuan iniciara uma investigação conceitual mais explicitamente humanista, que se consubstanciaria em importante contribuição para a fixação de uma identidade própria para a geografia humanista. Ao final dos anos 60 e início dos 70, seus trabalhos dedicavam-se a dois campos: a pesquisa das atitudes do homem em relação ao ambiente $(1967,1968,1971$ a, 1973), que culminaria com a publicação do livro Topophilia em 1974 (Tuan, 1980); a investigação sobre conceitos espaciais que fossem mais adequados do que o de "paisagem", utilizado usualmente pela geografia cultural, permitindo uma investigação com características mais subjetivas e antropocêntricas, além de adequar-se ao aporte filosófico fenomenológico, existencialista e estruturalista (TUAN 1971 b, 1972 a, 1972 b, 1975 a, 1975 b), investigação que culminaria com a publicação dos artigos Space and Place: humanistic perspective (1974. Republicado em coletânea de 1979), Humanistic Geography (1976), e do livro "Space and Place" (1977. TUAN, 1983). 
Considero que já em 1967 Tuan delineara um roteiro que indicava alguns caminhos que poderia seguir em suas pesquisas (TUAN, 1967). No ano seguinte o autor compararia atitudes européias e chinesas que levaram à substituição do ambiente natural por outro humanizado, simbolizado, no caso, pelos jardins europeus e chineses (TUAN, 1968). Esse assunto mereceria estudos mais elaborados com a publicação de Man and Nature (1971 a) e do artigo Ambiguity in Attitudes Toward Environment (TUAN, 1973).

Em "Ambiguity..." o autor reafirmaria opiniões emitidas em 1971 relativas às respostas ambíguas do homem ao ambiente físico, exceto, talvez, sob rígido controle no laboratório. Portanto, na investigação das atitudes e valores, que tanto interessavam aos geógrafos dedicados à pesquisa das dimensões psicológicas, estas respostas ambíguas deveriam ser estudadas:

“... a ambigüidade e a ambivalência são o resultado de três conjuntos principais de fatos ou de condições: 1) ambientes complexos (ou estímulos); 2) a discrepância entre a busca mental da simetria e o viés da intenção humana em relação aos valores específicos situados no futuro; e 3) a tendência polarizadora de sentimentos e de idéias primitivas." (TUAN, 1973, 411).

Estes três conjuntos, assunto central deste artigo de 1973, poderiam ajudar a desvendar o fenômeno da ambivalência da natureza humana, com o auxílio das humanidades, principalmente a literatura.

Topophilia (TUAN, 1980) marcaria o ápice das investigações de Tuan sobre as atitudes humanas em relação ao ambiente. Este livro se configura como extenso "catálogo" que examina as diversas alternativas de investigação. O autor considerava seu esforço integrado ao impulso ecológico-ambiental surgido nos anos 60 e que, segundo ele exigia, além de pesquisa aplicada, pesquisa teórica e científica.

O autor alertava para a disparidade entre objetivos, métodos, pressupostos filosóficos e escalas envolvidas nesta empreitada, que seriam unificados em um único tema: o modo como os seres humanos respondem a esse ambiente. Nenhum conceito abrangente, reconhece, une essas disparidades. Contenta-se, então, em estruturálas em torno da "topofilia", definida como o elo de afeição que une as pessoas aos lugares.

Sobre este material heterogêneo, utilizando-se em apoio ao conceito de "topofilia", dos conceitos de "percepção", "atitude" e "visão de mundo", Tuan distinguiria cinco tipos principais de questões ligadas às atitudes e valores ambientais:

“(1) Como os seres humanos, em geral, percebem e estruturam o seu mundo. São procurados traços humanos universais; (2) percepção e atitudes ambientais como a dimensão da cultura ou a interação entre a cultura e o meio ambiente. Pessoas analfabetas e comunidades pequenas são examinadas em algum detalhe e numa abordagem holística; (3) tentativas para inferir atitudes e valores ambientais com o auxílio de pesquisas, questionários e testes psicológicos; (4) mudanças na avaliação ambiental como parte de um estudo da história das idéias ou da 
história da cultura; (5) o significado e a história de ambiente como a cidade, o subúrbio, o campo e o selvagem. "(TUAN, 1980, 2).

Topophilia explora sistematicamente estes cinco campos: estuda os sentidos e os traços comuns da percepção; aborda os mundos individuais a partir das diferenças e preferências de cada um; investiga as percepções comuns a partir da cultura e das atitudes ambientais; estuda a cidade como síntese desses campos, pois o espaço humanizado seria a materialização das atitudes atuais e passadas para com o ambiente.

Nestes trabalhos voltados para as atitudes e valores ambientais Tuan não explicitava suas preocupações teóricas e filosóficas, entretanto desenvolvia, paralelamente, uma busca por embasamento teórico calcado na filosofia e no intercâmbio com outras disciplinas. Esta busca, inaugurada no artigo Geography, Phenomenology and the Study of Human Nature (TUAN, 1971 b), continuaria de forma intensa ao longo da década de 70.

Essas incursões pela filosofia e ciências afins iriam certamente embasar "Topophilia (TUAN, 1980), como pode ser evidenciado no estudo que ali é realizado sobre a evolução dos mundos pessoais analisados pela teoria da aprendizagem de Piaget. Essa base teórica é muito mais evidente no artigo Space and Place: Humanistic Perspective (TUAN, 1979), publicado em 1974. Este-é o primeiro que discute as possibilidades da geografia humanista como campo autônomo, fazendo um duo com Values in Geography, de Anne Buttimer (1974).

Em Space and Place: Humanistic Perspective, Tuan afirmava que "espaço" e "lugar" são os conceitos que definem a natureza da geografia. Introduzia também o tempo como conceito em constante interação com o espaço. $\mathrm{O}$ autor defendia a importância de sua investigação:

"Todo trabalho acadêmico aumenta o campo da consciência. Os estudos humanistas contribuem, ademais, para a auto-consciência, para o crescente conhecimento que o homem tem das fontes do seu saber. Em cada grande disciplina existe um subcampo humanista que é a filosofia e a história daquela disciplina. Através do subcampo, por exemplo, a geografia ou a física conhecem a si próprias, isto é, as origens de seus conceitos, pressuposições e viéses nas experiências de seus sábios e cientistas pioneiros.” (TUAN, 1979, 388)

O espaço na perspectiva humanista referia-se aos sentimentos espaciais e à experiência. Experiência definida como:

\footnotetext{
"a totalidade de meios pelos quais nós chegamos à compreensão do mundo: nós conhecemos o mundo através da sensação (sentimento), percepção e concepção. A compreensão do espaço pelos geógrafos é abstrata, embora menos que a do matemático puro" (TUAN, 1979, 388). Para Tuan "A importância do "lugar" para a geografia cultural e humanista é, ou deveria ser, óbvia. Como nós funcionais no espaço, os lugares sujeitam-se as técnicas da análise espacial.
} 
Mas como um único e complexo conjunto - enraizado no passado e crescendo no futuro e como símbolo, o lugar clama pelo entendimento humanista. Na tradição humanista os lugares tem sido estudados a partir das perspectivas histórica e literário-artística ... Nos falta, contudo, análise sistemática ... Exceto a dissertação de Edward Relph, a literatura sobre este tópico - seguramente de importância central para os geógrafos - tem sido, e continua sendo, negligenciada. Aprendemos a apreciar a análise espacial, a erudição histórica e a fina prosa descritiva, mas o entendimento filosófico, baseado no método e ponto de vista dos fenomenologistas, ainda está além do alcance de nossos conhecimentos. Neste ensaio será introduzida a perspectiva fenomenológica. Não me deterei, no entanto, apenas nela e tentarei evitar uma linguagem técnica." (TUAN, 1979, 389).

Tuan, neste artigo, recorreu aos textos de geógrafos como Humboldt, Sauer, Glacken, Lowenthal e Dardel (seguramente introduzido na geografia norte-americana por Relph em sua dissertação de 1973); de filósofos como Kockelmans, MerleauPonty, Schutz, Heidegger, Van der Leew, Piaget, Cassirer, Bergson e Ricoeur; antropólogos como Boas, Evans-Pritchard e Whorf. Munido deste aparato bibliográfico investigava as relações entre espaço e tempo e as características do "espaço" e do "lugar".

Para Tuan tempo e espaço estão ligados pela noção de distância, ambos os conceitos orientados e estruturados pela intencionalidade do ser (TUAN, 1979, 390). Deste modo, espaço e tempo são inseparáveis na atividade locomotora, apesar de serem separáveis na fala e no pensamento.

Se por um lado esta espacialização da matéria exige um comportamento ativo, por outro, o homem é feito pelo ambiente geográfico. A distância é um elemento primordial deste ambiente que age sobre o homem, sendo assim primordial para a estruturação do mundo que nos rodeia.

Dardel já destacava esta qualidade estrutural ao comentar

"Que o espaço geográfico aparece essencialmente qualificado em uma situação concreta que afete o homem, é o que prova a espacialização cotidiana que o espacializa como afastamento e direção. As distâncias geográficas não provêm de uma medida objetiva, auxiliada por unidades de distância previamente desenvolvidas. Ao contrário, o cuidado de medir exatamente resulta desse cuidado primordial que o homem carrega com ele, de colocar a seu alcance as coisas que o cercam. A distância é experimentada não como uma quantidade, mas como uma qualidade exprimida pelos termos perto e longe." (DARDEL, 1990[1952]).

\section{Desta experiência fundamental Dardel extrai outras relações de distância:}

"As direções foram então fixadas, elas também, por necessidades práticas. Ao mesmo tempo que procura tornar as coisas próximas, o homem necessita se dirigir, por sua vez, para se reconhecer no mundo circundante, para aí se encontrar, e para manter reta sua caminhada e para abreviar as distâncias. Um homem expatriado é um homem 'desorientado'; hesitar é, em 
todos os sentidos, hesitar sobre a direção a tomar." (DARDEL, 1990 [1952], 14).

O marco referencial é o próprio corpo e o suporte onde ele se instala: a casa da família, a vila natal, as colinas. A partir destas lembranças afetivas e imaginárias surge a linguagem geográfica, que exprime

“... as surpresas, as privações, os sofrimentos ou as alegrias que se ligam às regiões." (DARDEL, 1990 [1952], 15).

Constitui-se, assim, a noção de espaço primitivo, que envolve nossos pensamentos, vontades e desejos. Este espaço primitivo é definido por Dardel como

"[um] espaço englobando o espaço material, mas mais próximo, sem nenhuma dúvida, do espaço geográfico concreto que do espaço geométrico. Espaço onde se desenvolve a existência, porque ela é, em essência, extensão, por que ela procura um horizonte, direções, existências a se aproximar dela, por que a vida lhe oferece percursos a seguir, fáceis ou acidentados, seguros ou incertos. Ali onde os termos não podem mais se agarrar à uma realidade que resiste e que responde e não são mais do que cifras, é a geografia que, naturalmente, fornece seu vocabulário porque ele é concreto e qualitativo, próximo e claro." (DARDEL, 1990 [1952], 17).

\section{A direção e a distância definem a situação, que é}

“... é um sítio estável e inerte.” (DARDEL, 1990 [1952], 18). Este conceito de situação delineia o arcabouço da geograficidade (geographicité): "Do plano da geografia, a noção de situação extravasa para os domínios mais variados da experiência do mundo. A 'situação' de um homem supõe um 'espaço' onde ele 'se move'; um conjunto de relações e de trocas; direções

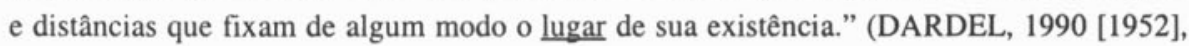
19).

Tuan observava que os filósofos, com exceção dos kantianos, sejam fenomenologistas ou positivistas, priorizam o tempo em função do espaço. Isso acontece porque os filósofos estão interessados na natureza da causa, colocando-a sob a luz do tempo, pois pensam no fluxo do tempo como determinante das conexões causais dos fenômenos; o espaço, por sua vez, só ordena os dados coexistentes (TUAN, 1979, 391).

Os ocidentais, no entanto, quando se utilizam da linguagem tendem a espacializar os termos que denominam o tempo, enquanto que nos idiomas não-ocidentais não existe esta tendência, existe um vocabulário autônomo para denominar as ações temporais.

Conclui Tuan:

“A experiência e apreensão do espaço é substancialmente a mesma independentemente da linguagem. Neste sentido, o espaço é mais básico para a experiência humana do que o tempo, 
cujo significado varia fundamentalmente de povo para povo." (TUAN, 1979, 393).

O espaço, diz Tuan, é orientado e estruturado a partir do corpo humano. Como os fenomenologistas e os antropólogos observaram, estas relações primitivas têm o corpo como um sistema de funções que podem servir de instrumento para a escolha consciente e no direcionamento das intenções para um determinado campo (TUAN, 1979, 389).

Além dessa experiência primitiva do espaço ligada ao ego, existe, como Tuan explica, a experiência pessoal de espaço:

"A estrutura e o tom sentimental do espaço estão unidos ao equipamento perceptivo, à experiência, ao temperamento e propósito do indivíduo humano. Nós adquirimos conhecimento do mundo através das possibilidades e limitações dos nossos sentidos. $\mathrm{O}$ espaço que nós podemos perceber estende-se na frente e ao redor de nós, e é divisível em regiões de qualidades diversas. Removendo o mais distante e cobrindo a mais vasta área está o espaço visual. Ele é dominado pelo horizonte amplo e por objetos pequenos e indistintos. Esta região puramente visual parece estática ainda que as coisas se movam em seu interior...

Ao caracterizar a estrutura do espaço, eu introduzo os termos passado, presente e futuro. A análise da experiência espacial parece requerer o uso de categorias temporais. Isso porque nossa consciência das relações espaciais dos objetos não é jamais limitada às percepções dos objetos em si: a consciência do presente está, em si, imbuída das experiências passadas em movimento e tempo, com memórias de gastos passados de energia, ela é movida em direção ao futuro pelas demandas de ação dos objetos perceptivos." (TUAN, 1979, 398-400).

Além do espaço pessoal, existe a experiência grupal do espaço, onde é vivida a experiência do outro. É o que os fenomenologistas chamam de intersubjetividade. Este é o caso do fenômeno do "apinhamento", que Tuan escolhe como exemplo para este artigo.

Outro tipo de espaço que o autor considera é o "espaço mítico-conceitual”, que é o produto das generalizações produzidas pela mente, situando-se, na gama das experiências, entre o sentido da percepção e o espaço puro da cognição:

"O espaço mítico-conceitual está sempre ligado ao ego e à experiência direta, mas ele extrapola para além da evidência sensorial e das necessidades imediatas em direção das estruturas mais abstratas do mundo." (TUAN, 1979, 404).

Investigados os diversos significados de espaço, Tuan iria se dedicar ao lugar. Ele observa que o lugar, na linguagem coloquial, tem dois significados: posição na sociedade e localização espacial. Mas, além destes, tem outro mais profundo: ele possui "espírito", "personalidade", existe um "sentido do lugar" (TUAN, 1979, 409). Este sentido do lugar remete-se à apreciação visual ou estética, e também pela audição, olfato, paladar e tato, que exigem um contato próximo e uma longa associação com o ambiente. 
Tuan distinguiria a cena (scene) ou paisagem do lugar:

“Uma cena pode ser um lugar, mas a cena em si não é um lugar. Falta-lhe estabilidade: é da natureza de uma cena a propriedade de se alterar a partir de cada mudança de perspectiva. Uma cena é definida por sua perspectiva, enquanto que isso não é verdadeiro para o lugar: é da natureza do lugar que ele apareça como possuindo uma existência estável independente do indivíduo que o percebe." (TUAN, 1979, 411).

Conclusão do autor: o espaço e o lugar são os assuntos centrais da geografia. Estes assuntos são vistos pelos positivistas através da análise da organização espacial, para os humanistas assumem outras características. Ambas as perspectivas teriam validade: os conceitos positivistas interessam aos humanistas porque são o exemplo extremo da tendência universal para a abstração; os trabalhos humanistas podem interessar aos positivistas porque promovem o auto-conhecimento, utilizando-se do seu mais alto valor, as humanidades (TUAN, 1979, 422).

Esta investigação de Tuan acerca do lugar como conceito mais apropriado para a geografia humanista, continuaria nos anos seguintes, culminando com a publicação do livro Space and Place: the perspective of experience em 1977 (TUAN 1983). Neste intervalo, de 1974 a 1977, Tuan estudaria também os mapas mentais. Em Images and Mental Maps (TUAN, 1975 b) ele advertia que o estudo da percepção na geografia, apesar de novo, necessitava de uma pausa para reconsiderar os fundamentos e modos de seus questionamentos, sendo que também através do estudo da imagem e do "schemata" pode-se descobrir os fenômenos mentais que interessam ao geógrafo e à curiosidade do homem comum.

Em Place: an experential perspective (TUAN, 1975 a), caracterizava o lugar a partir da experiência. O lugar era avaliado como lar, em suas diversas escalas: o próprio lar, a vizinhança, a cidade, a região (a qual atribuía características semelhantes à da vizinhança), e ao estado-nação. Discutia também o papel da arte, da educação e da política na formação da experiência que torna os lugares visíveis.

Space and Place: the perspective of experience (TUAN, 1983) é a consolidação destas investigações. A questão central do livro é: o que são o espaço e o lugar em termos de experiência humana? Aqui não é explicitada a base fenomenológica, mas na introdução o autor chama a atenção para as questões formuladas pelos humanistas para o espaço e o lugar (TUAN, 1983, 7).

Este livro agrupava temas que o autor pesquisava há anos: o corpo e os valores espaciais; a sensação de apinhamento como expressão da relação intersubjetiva; a variabilidade das habilidades espaciais em função da experiência; o espaço mítico extrapolando a visão pessoal do mundo; a inter-relação entre tempo e lugar; o espaço arquitetônico como síntese da criação do espaço humanizado. Tuan, com toda certeza, foi dos principais responsáveis pela valorização do "lugar" como conceito central dos estudos geográficos. 
O CONCEITO DE LUGAR NA GEOGRAFIA CULTURAL-HUMANISTA: UMA CONTRIBUIÇÃO PARA A GEOGRAFIA CONTEMPORÂNEA

Resumo: A Geografia Humanista inovou no conceito de espaço e de lugar, ao desenvolvê-los no sentido da Fenomenologia. O texto analisa sobretudo as concepções de Tuan.

Palavras-chave: Geografia Humanista, Espaço, Lugar.

\section{CONCEPT OF PLACE AT CULTURAL-HUMANISTIC GEOGRAPHY: A CONTRIBUTION} TO A CONTEMPORANEOUS GEOGRAPHY

Abstract: Humanistic Geography has innovated the concepts of space and place, as develops them in the sense of phenomenology. This text analyzes mainly the conceptions of Tuan

Key words: Humanistic Geography; Space; Place

\section{BIBLIOGRAFIA}

BUTTIMER, Anne. (1974). Values in Geography. Washington, AAG

BUTTIMER, Anne. (1976). Grasping the dinaminsm of lifeworld. Annals of the Association of American Geographers. 66 (2) : 266-276.

DARDEL, Eric. (1990). L'Homme et la Terre - Nature de la Réalité Géographique. Paris, Ed. CTHS. (1ª ed. Paris, PUF, 1952).

HOLZER, Werther. (1993). A geografia humanista anglo-saxônica - de suas origens aos anos 90. Revista Brasileira de Geografia. 55 (1/4) : 109-146.

HOLZER, Werther. (1996). A geografia humanista: uma revisão. Espaço e Cultura.

(3) : 8-19. HOLZER, Werther. (1999). O lugar na geografia humanista. Território. (7) : 67-78.

MIKESELL, Marvin. (1978).Tradition and innovation in cultural geography. Annals of the Association of American Geographers. 68 (1) : 1-16.

RELPH, Edward. (1970). An inquiry into the relations between phenomenology and geography. Canadian Geographer. 14 (3) : 193 -201.

RELPH, Edward. (1976). Place and Placenessless. London, Pion.

SAUER, Carl Ortwin. (1981). On the backgrounds of geography in the United states. in: Callahan, B. (ed.). Selected Essays 1963-1975 - Carl O. Sauer. Berkeley, Turtle Island Foundation. P. 241-259.

SAUER, Carl Ortwin. (1998). A morfologia da paisagem. in: Corrêa, R. L. e Rosendahl, Z. (Orgs.). Paisagem, Tempo e Cultura. Rio de Janeiro, EdUERJ. (1 ${ }^{\mathrm{a}}$ ed. Berkley, Univ. of California, 1925).

TUAN, Yi-Fu. (1967). Attitudes toward environment: themes and approaches. In:

Lowenthal, D. (ed.): Environmental Perception and Behavior. Chicago, The University of Chicago.

TUAN, Yi-Fu. (1968). Discrepancies between environmental attitude and behavior: exemples from Europe and China. Canadian Geographer. 12 (2) : 176-191. TUAN, Yi-Fu. (1971 a). Man and Nature. Washington, AAG

TUAN, Yi-Fu. (1971b). Geography, phenomenology and the study of human nature.

Canadian Geographer. 15 (2) : 181-192. 
TUAN, Yi-Fu. (1972 a). Environmenthal psychology: a review. Geographical Rewiew. 62 (2): 245-256.

TUAN, Yi-Fu. (1972 b). Structuralism, existentialism and environmental perception. Environment and Behavior. 4 (3) : 319-331.

TUAN, Yi-Fu. (1973). Ambiguity in attitudes toward environment. Annals of the Association of American Geographers. 63 (4) : 411-423.

TUAN, Yi-Fu. (1976). Humanistic Geography. Annals of the Association of American Geographers. 66 (2) : 266-276.

TUAN, Yi-Fu. (1975 a). Place: na experential perspective. Geographical Review. 65 (2) : 151-165.

TUAN, Yi-Fu. (1975 b). Images and mental maps. Annals of the Association of American Geographers. 65 (2) : 205-213.

TUAN, Yi-Fu. (1979). Space and place: humanistic perspective. In: Gale, S.; Olsson, G. (eds.) Philosophy in Geography. Dordrecht, Reidel Publ. Co., p. 387-427. (publicado originalmente em: Progress in Geography. (6) : 211-252, 1974)

TUAN, Yi-Fu. (1980). Topofilia: um estudo da percepção, atitudes e valores do meio ambiente. São Paulo/Rio de Janeiro, DIFEL. $\left(1^{\text {a }}\right.$ ed. norte-americana: Topophilia: a study of environmental perception, attitudes, and values. Englewood Cliffs, Prentice-Hall, 1974).

TUAN, Yi-Fu. (1983). Espaço e Lugar: a perspectiva da experiência. São Paulo/ Rio de Janeiro, DIFEL. ( $1^{\mathrm{a}}$ ed. norte-americana: Space and Place: the perspective of experience. Minneapolis, University of Minnesota Press, 1977). 